\title{
BMJ Open Effect of second child intent on delivery mode after Chinese two child policy implementation: a cross sectional and prospective observational study of nulliparous women in Chongqing
}

Jianlin Zhao, ${ }^{1}$ Nan Shan, ${ }^{1}$ Xiaochang Yang, ${ }^{1}$ Qin $L i,{ }^{1}$ Yinyin Xia, ${ }^{2}$ Hua Zhang, ${ }^{1}$ Hongbo Qi ${ }^{1}$

To cite: Zhao J, Shan N, Yang $\mathrm{X}$, et al. Effect of second child intent on delivery mode after Chinese two child policy implementation: a cross sectional and prospective observational study of nulliparous women in Chongqing. BMJ Open 2017;7:e018823. doi:10.1136/ bmjopen-2017-018823

- Prepublication history and additional material for this paper are available online. To view these files, please visit the journal online (http://dx.doi org/10.1136/bmjopen-2017018823).

Received 24 July 2017 Revised 26 September 2017 Accepted 25 0ctober 2017

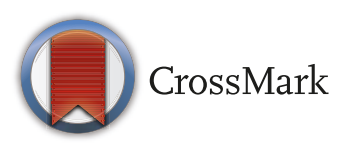

${ }^{1}$ Department of Obstetrics and Gynaecology, First Affiliated Hospital of Chongqing Medical University, Chongqing, China ${ }^{2}$ School of Public Health and Management, Research Center for Medicine and Social Development, Innovation Center for Social Risk Governance in Health, Chongqing Medical University, Chongqing, China

Correspondence to

Profosser Hongbo Qi; qihongbocy@gmail.com

\section{ABSTRACT}

Objectives To assess the influence of second child intent on the delivery preferences and final delivery modes of nulliparous women, particularly caesarean delivery on maternal request (CDMR), after implementation of China's two child policy.

Design Cross sectional and prospective observational study.

Setting A tertiary teaching hospital in Chongqing, China. Participants 1000 low risk nulliparous women were initially involved, and were divided into two groups based on their intent on having a second child. 814 women who completed all interviews were analysed.

Main outcome measures Preferred mode of delivery in second trimester and at admission; final delivery mode, CDMR.

Results 814 women who completed all interviews were analysed, in whom $51.2 \%$ intended to have a second child. The preference for caesarean delivery (CD) at the second trimester between the intent and no intent group was $6.2 \%$ versus $17.9 \%$ (adjusted RR $0.35,95 \% \mathrm{Cl} 0.20$ to 0.63 ) and increased to $24.2 \%$ versus $37.3 \%$ (adjusted RR $0.65,95 \% \mathrm{Cl} 0.45$ to 0.94 ) at admission, respectively. The overall CD rates between the two groups were $41.0 \%$ versus $50.4 \%$ (adjusted $\mathrm{RR} 0.84,95 \% \mathrm{Cl} 0.60$ to 1.18 ), and the CDMR rates were $16.7 \%$ versus $29.0 \%$ (adjusted RR $0.56,95 \% \mathrm{Cl} 0.37$ to 0.86 ), respectively.

Conclusions Women who intend to have a second child are less likely to request a $C D$, and high rates of $C D$ and CDMR in nulliparous women may have decreased after implementation of China's two child policy.

\section{INTRODUCTION}

The rate of caesarean delivery (CD) has increased dramatically in recent decades worldwide, particularly in developing countries. ${ }^{1}$ WHO surveys showed that the average rate of CD in Latin America was 33\% and in Asia $27.3 \%$, of which China had a disproportionately high rate of $\mathrm{CD}$ of $46.2 \% .^{23}$ Several studies have shown that China's caesarean rate exceeds $50 \%{ }^{4-6}$ A multicentre study

\section{Strengths and limitations of this study}

- To the best of our knowledge, this study is the first attempt to estimate the influence of second child intent on delivery preference and ultimately final caesarean delivery (CD), especially caesarean delivery on maternal request (CDMR), in nulliparous women, after implementation of China's new population control policy.

- It is a cross sectional and prospective study following a number of pregnant women from the second trimester of pregnancy to postpartum.

- Participants were selected from a tertiary hospital located in the centre of Chongqing district and the sample size was relatively small, both of which may affect the generalisability of the results.

- The study population was predominantly an urban population, with a higher education level, which may have led to a higher $\mathrm{CD}$ rate.

- Although we adjusted for various potential confounders, including age, given the nature of the observational study, in particular that the no intent group had a much higher proportion of mothers of advanced age ( $\geq 35$ years) than the intent group ( $9.8 \%$ vs $1.4 \%)$, residual confounding likely still existed that might have an effect on the association between exposure variables and outcomes.

conducted by Liu et al, including 39 hospitals in 14 provinces, showed that the overall CD rate in 2012 was $54.9 \%$, and the caesarean delivery on maternal request (CDMR) rate was $28.43 \% .^{5}$ Another analyses by Zhang et al showed that the overall caesarean rate in southeast China increased from $22 \%$ in 1994 to $60 \%$ in 2003 , and moderated to $56 \%$ in 2006, and the rate of CDMR was $0.8 \%, 22 \%$, and $20 \%$, respectively. ${ }^{7}$ Recently, a more detailed survey 'Geographic Variations in Caesarean use in China from 2008 
to 2014', showed that the $\mathrm{CD}$ rate in Chongqing district was $43.0 \%$ in 2008 and increased to $49.5 \%$ in $2014 .{ }^{8}$ Also, studies have indicated that excessive use of $\mathrm{CD}$, particularly in the absence of clear surgical conditions, may increase maternal and infant long term morbidity and mortality ${ }^{9-12}$ Also, the risk of placenta praevia, placenta accrete and uterine rupture can increase significantly in the next pregnancy after a primary $\mathrm{CD} .{ }^{13-16}$

China's population control policy was implemented 30 years ago which aimed at regulating family size and stipulated that the majority of women could deliver only once, resulting in few repeat CDs. An analysis of hospital discharge data, including 39 hospitals in 14 provinces of China in 2011, concluded that $81.4 \%$ of women were having their first birth, and less than $8 \%$ of deliveries were to women who had a previous $\mathrm{CD} .{ }^{6}$ Owing to the one child policy, women were not concerned about future pregnancies, creating a demand for a perfect outcome. ${ }^{47}$ In addition, high coverage rate of medical insurance promoted by the Chinese government lowered out of pocket expenses for patients having a CD. ${ }^{47}$ As a result, CD was viewed as a 'painless' and 'convenient' method to complete pregnancy for women. Also, more relaxed surgical criteria to avoid potential risks due to the tense doctor-patient relationship in China and extra payment from CD operations, combined with other factors, such as socioeconomic changes and new monitoring technologies, have contributed to the popularity of CD, particularly CDMR, in China. ${ }^{48-21}$

On 15 November 2013, China relaxed the population control policy, and a more universal policy, which allows all families to have two children, was subsequently announced on 29 October 2015. ${ }^{22}{ }^{23}$ Before the new policy, many women received an elective $\mathrm{CD}$ because they believed that they would have no further pregnancies. Morbidity and mortality associated with subsequent pregnancies after a primary $\mathrm{CD}$ are not frequently observed by obstetricians, but conditions will change following relaxation of the policy. It is estimated that 90 million couples can have a second child, of whom $25 \%$ will decide to have a second child, and many will have had a CD for the first delivery. ${ }^{24}$ However, because of the lack of experience, skills and resources necessary to manage a safe vaginal birth after CD, most women with a scarred uterus will have a repeat $\mathrm{CD}$ for their second delivery, with increased risks of postpartum haemorrhage, severe adhesion, uterine rupture and even hysterectomy. ${ }^{25} \mathrm{~A}$ study showed that if a woman has a placenta previa and one prior $\mathrm{CD}$, the risk of placenta accreta is $11-24 \% .{ }^{26}$ The Chinese hospital and obstetricians will be challenged as more women have repeat CDs or vaginal births after $\mathrm{CD}$. Therefore, policies aimed at the safe prevention of primary CD in China may become a priority for both doctors and the government.

The new policy will not only make obstetricians begin to consider the consequences caused by the high rates of primary CDs, but may change women's perceptions about CD, especially those who intend to bear two children. Therefore, we performed this study to preliminarily address issues of whether preferences for $\mathrm{CD}$ and CDMR would be decreased in those nulliparous women who want two babies. This information will be useful for identifying new strategies to lower China's high CD rate.

\section{METHODS}

\section{Study design and data collection}

This study was conducted in a university based tertiary care centre in southwest urban China from 1 January 2016 to 31 July 2016. Pregnant women who received their antenatal care and met the inclusion criteria were asked if they would be willing to participate in the study. Inclusion criteria were: (1) older than 20 years; (2) nulliparous woman with singleton pregnancy; (2) no history of severe heart, liver, lung, kidney, endocrine or psychiatric diseases resulting in hospitalisation at recruitment; (3) no severe pregnancy complications in the first interview (mainly including early onset pre-eclampsia, severe intrahepatic cholestasis of pregnancy); and (4) planning to give birth at the hospital. Those who (1) did not respond to the first interview or missed the second interview, (2) had a multiple pregnancy, (3) had a previous uterine scar before pregnancy (mainly from myomectomy), (4) delivered at $<36^{+0}$ weeks' gestation or (5) had existing medical indications for $\mathrm{CD}$ at the first interview were excluded before the analyses.

We performed the first interview at $24^{+0}-28^{+6}$ weeks' gestation (second trimester), during which the women received system ultrasonography to exclude fetal congenital abnormalities. Nurses were trained to explain the objectives of the study. Women who consented to the study were given a self-administered questionnaire, including general characteristics and preferred mode of delivery ( $\mathrm{CD} /$ vaginal delivery/nopreference). The intent to have a second child as an exposure variable was also listed as a choice question, in a yes/no format, and the women were then divided into two groups based on the intent. Those who did not want a second child were asked a multiple choice question to determine the reason. For those women who chose vaginal delivery as their first option in the intent group, another multiple choice question was asked to determine the reason. The questionnaires were designed by experts from the Chongqing Medical University (epidemiology experts, health education experts and obstetric experts).

After attending the first interview, women were given a second interview at admission, and those who did not eventually deliver at our hospital and whose delivery age was $<36^{+0}$ weeks were also excluded at this stage. During the second interview, their preferred mode of delivery was obtained again. Types of information that were abstracted from the medical record included obstetric complications, reproductive and prenatal history, labour and delivery records, postpartum and neonatal information, and history of pre-existing conditions before pregnancy. Women whose medical history included a previous uterine scar before pregnancy (mainly from myomectomy) were 
excluded. The interview information and discharge data were then merged and de-identified prior to the analyses. The main outcomes of the study were delivery preference in the second and third trimesters and the final CD, especially CDMR, between the two groups.

\section{Definitions}

Labour was defined as regular uterine contractions and cervical dilation of $2 \mathrm{~cm}$. CD performed before labour was categorised as an antepartum CD, whereas intrapartum $\mathrm{CD}$ was defined as an operation performed after labour. As there are no internationally recognised indications for $\mathrm{CD},{ }^{27}$ we used the national caesarean delivery consensus compiled by the Chinese Medical Association in 2014 to assess if the cases had justified indications for $\mathrm{CD} .^{28}$ Moreover, we grouped the indications for CD into four categories following the criteria of Liu et al: CDMR before labour without any medical indications; antepartum CD with borderline indications; antepartum $\mathrm{CD}$ with medical indications; and intrapartum CD after a trial of labour. ${ }^{29} 30$ Furthermore, combined with the specific circumstances in this hospital, we added mild intrahepatic cholestasis of pregnancy, failed induction of labour, fetal growth restriction and marginal placenta previa to the group of antepartum $\mathrm{CD}$ with borderline indications.

The medical history included the presence of chronic diseases and/or reproductive surgery before pregnancy, including chronic hypertension without superimposed pre-eclampsia/eclampsia, type I or type II diabetes with or without macrosomia, asthma requiring medical intervention, arrhythmia requiring intervention during pregnancy, thalassaemia with mild or moderate anaemia, hyperthyroidism or hypothyroidism, chronic kidney disease (stages 1 and 2), connective tissue disease without severe oranges damage, polycystic ovary syndrome with assisted reproduction, epileptic seizure occurring during pregnancy, malignancy requiring surgery or chemotherapy before pregnancy, infectious disease which required medication such as hepatitis B virus, cervical conisation before pregnancy, tubectomy due to ectopic pregnancy, and unilateral or bilateral adnexectomy. Pregnancy complications included diseases occurring in pregnancy, including gestational diabetes mellitus with macrosomia, late onset pre-eclampsia/eclampsia, mild intrahepatic cholestasis of pregnancy, overt hyperthyroidism or hypothyroidism, thrombocytopenia requiring platelet transfusion, thrombosis with inferior vena cava filter placing, fetal growth restriction and placenta previa. Maternal and neonatal outcome were collected but not considered in the analyses.

\section{Statistical analysis}

Statistical analysis was performed using the SPSS V.20 (IBM; Armonk, New York, USA). Categorical data were evaluated with the $\mathrm{x}^{2}$ test or Fisher's exact test when the expected cell count was $<5$. Continuous variables were compared using two sample t tests. A series of logistic regressions were used to estimate the magnitude of influence of the intent to have a second child on outcome using RR by adjusting potential explanatory variables that were ascertained as variables with an association of $\mathrm{p}<0.1$ at the univariate analysis. We added educational level, average income of the family, medical history, pregnancy complications, and maternal and neonatal morbidity into all of the models that were associated with delivery mode, ${ }^{19}$ even if there were no significance differences between the two groups: 95\% CI were also calculated for all outcomes. All analyses were two sided, and a probability value $<0.05$ was considered significant.

\section{RESULTS}

A total of 1000 women who satisfied the inclusion criteria were initially enrolled in their second trimester. Of these, 904 women $(90.4 \%)$ completed the first interview, of whom 51.2\% (463/904) intended to have a second child. We then divided the women into two groups based on their intent to have a second child. A total of 84 women did not deliver in our hospital, including 42 women in the intent group and 42 women in no intent group. For these women, we did a follow-up postpartum by telephone, and most delivered in a hospital near their home for emergency reasons. As they did not know the specific indications for their $\mathrm{CD}$, we asked for their final mode of delivery (vaginal delivery or $\mathrm{CD}$ ). Their baseline characteristics were collected from the questionnaire acquired in the first interview. The final $\mathrm{CD}$ rates between the two groups were $42.9 \%$ and $45.2 \%$, which were close to the rates in the analysis groups $(41.0 \%$ and $50.4 \%)$, and other characteristics also showed no difference (detailed information can be found in the online supplementary file). Four women had a gestational age $<36^{+0}$ weeks and two women had uterine scars; these women were excluded before the analyses. Finally, 814 women were enrolled in the final analysis. A flowchart of the study design is shown in figure 1 .

\section{Baseline and obstetric characteristics}

Only age and insurance status were statistically different between the two groups (table 1). Those who did not intend to have a second child were older and had a higher ratio of insurance.

\section{Reasons for no intent to have a second child and preferring vaginal delivery at first interview}

For those who stated they did not intend to have a second child, a follow-up multiple choice question asked why, and 441 women responded to the question. The most commonly cited reasons were time famine $(56.0 \%)$ and economic pressures $(55.7 \%$ ) (figure 2). In the intent group for those who stated they preferred a vaginal delivery, a follow-up multiple choice question asked why, and 417 women responded to the question. The most commonly cited reasons were rapid recovery $(82.2 \%)$ and beneficial for the next delivery $(76.7 \%)$ (figure 3 ). 


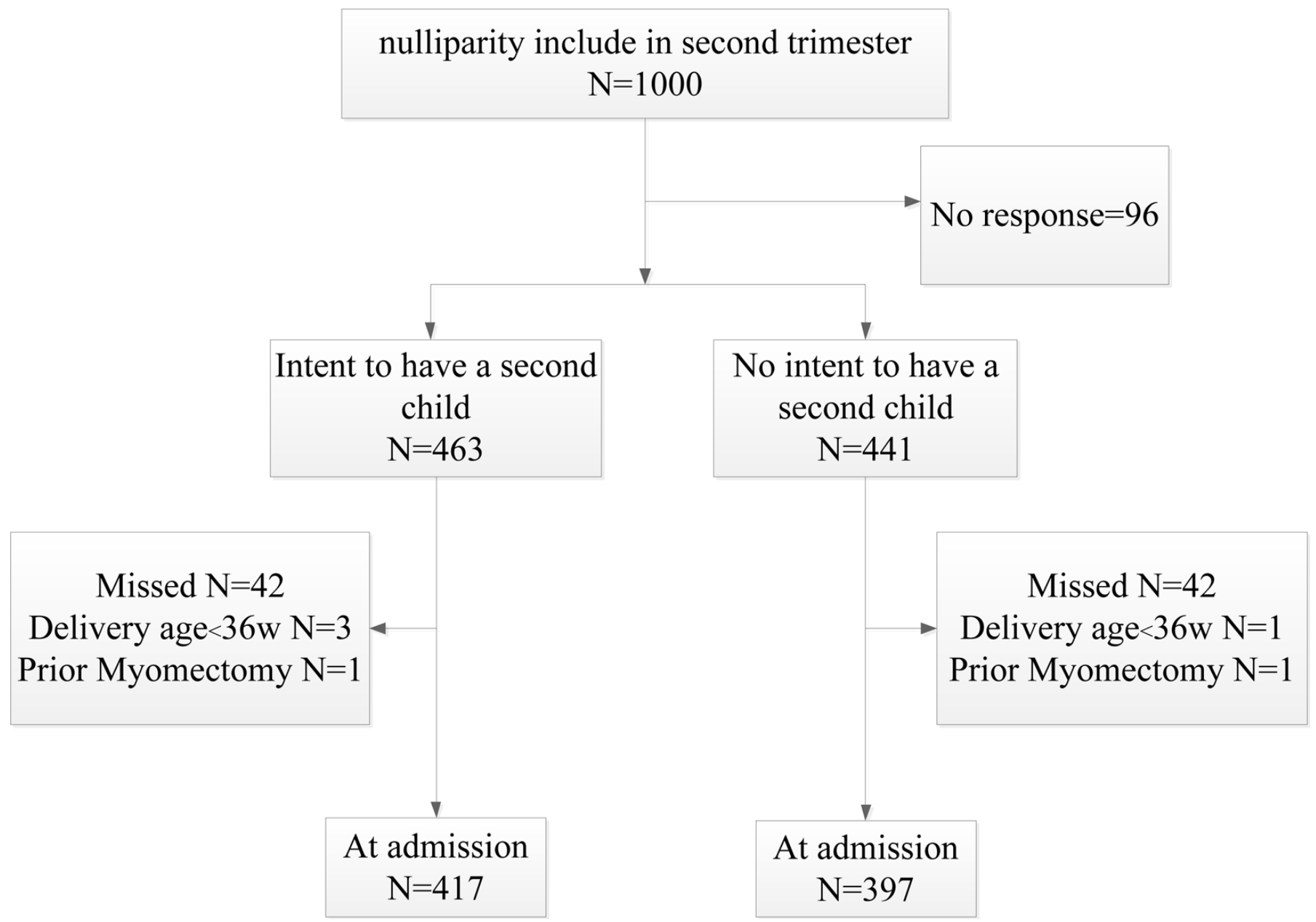

Figure 1 Flowchart of the study design.

\section{Preferred mode of delivery at the second trimester and at admission}

The overall preference for CD was $11.9 \%(97 / 814)$ in the second trimester, which significantly increased to $30.6 \%$ (249/814) at admission (table 2). Consistent with this, the preference rates for $\mathrm{CD}$ among those who did and did not desire a second child were $6.2 \%$ and $17.9 \%$ (crude RR (cRR) $0.31,95 \%$ CI 0.19 to $0.49, \mathrm{p}<0.05$ ) in the second trimester, which increased to $24.2 \%$ and $37.3 \%$ (cRR 0.54, $95 \%$ CI 0.40 to $0.73, \mathrm{p}<0.05)$ at admission, respectively. These results showed significant differences between the two groups, regardless of the stage of pregnancy. Those who only wanted one child were more likely to select CD compared with those who wanted a second child.

\section{Overall CD and CDMR rates}

The overall CD rates for those who did and did not desire a second child were $41.0 \%$ versus $50.4 \%$ (cRR 0.69 , 95\% CI 0.52 to $0.90, \mathrm{p}<0.05)$, and the CDMR rates were $16.7 \%$ versus $29 \%$ (cRR $0.48,95 \%$ CI 0.33 to 0.71 , $\mathrm{p}<0.05$ ), respectively. Although there was a slight increase in antepartum $\mathrm{CD}$ with borderline indication, no statistically significant difference was noted. No significant differences between other indications were apparent.
Independent strength of second child intent on delivery preference and final mode of delivery

Confounders that were found to have an association with outcomes were entered into a series of logistic regressions to determine the independent influence of intent status on outcomes (table 2). Reductions in the prefer CD in second trimester (adjusted RR (aRR) 0.35, 95\% CI 0.20 to $0.63, \mathrm{p}=0.001$ ), prefer $\mathrm{CD}$ at admission (aRR $0.65,95 \%$ CI 0.45 to $0.94, \mathrm{p}=0.02$ ) and CDMR (aRR $0.56,95 \%$ CI 0.37 to $0.86, p=0.008$ ) remained significant after adjustment, although the overall CD (aRR 0.84, $95 \%$ CI 0.60 to $1.18, \mathrm{p}=0.31$ ) was no longer significantly different after accounting for the influence of potentially confounding variables.

\section{DISCUSSION}

This observational study found that nulliparous women who intended to have a second child were less likely to request $\mathrm{CD}$. To the best of our knowledge, this study is the first attempt in China to estimate the influence of second child intent on nulliparous women's delivery preference and final CD, particularly CDMR, after China's two child policy implementation. 
Table 1 Baseline and obstetric characteristics of participating women $(n=814)$

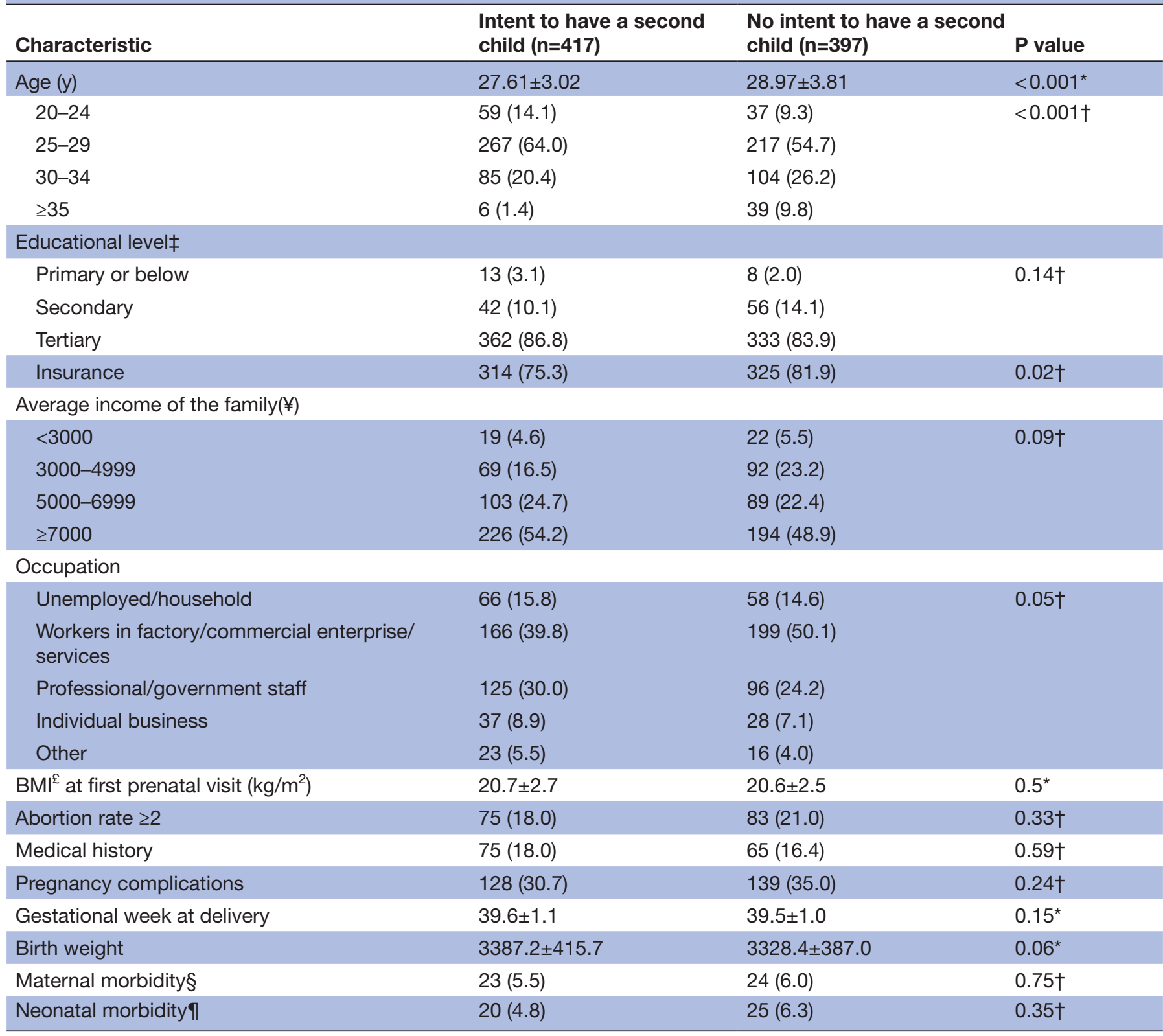

Data are mean \pm SD or $\mathrm{n}(\%)$.

${ }^{*}$ Two sample t test.

$\dagger \mathrm{x}^{2}$ test.

łEducation level was categorised as primary (primary school, junior middle school) or below, secondary (a senior high school, vocational/ technical secondary school and junior college) and tertiary (senior college and university).

§Including postpartum haemorrhage, puerperal infection, maternal organ injury and intensive care unit admission.

१Neonatal morbidity was defined as including any of the following outcomes: shoulder dystocia, birth injury, 5 min Apgar score $<7$, umbilical artery $\mathrm{pH}<7.0$, umbilical artery base deficit $>12$, requiring antibiotics for $>48$ hours and neonatal intensive care unit admission. Neonatal birth injury was defined as cephalohaematoma, fracture, intracranial haemorrhage or brachial plexus injury associated with delivery.

£BMI, body mass index.

As noted previously, with the one child policy, typical families in China with four grandparents and two parents waited for a 'perfect' baby which, combined with the belief that they would deliver only once, made CDMR the most common reason for $\mathrm{CD}$ in most areas of China. The new two child policy will not only increase the decreasing fertility rate in China but may alter the misconceptions about $\mathrm{CD}$ and CDMR, which will impact on the overall
CD rate. Our results indicate that women who intend to have two children are less likely to choose CD as their first choice, and the difference remained significant after adjusting for confounding bias. Furthermore, multiple choices questions were used to determine why women selected vaginal delivery as their first delivery preference in the intent group, and the results showed that $76.7 \%$ of women thought vaginal delivery was beneficial 
Figure 2 Frequency distribution of the reasons why women did not intend to have a second child.

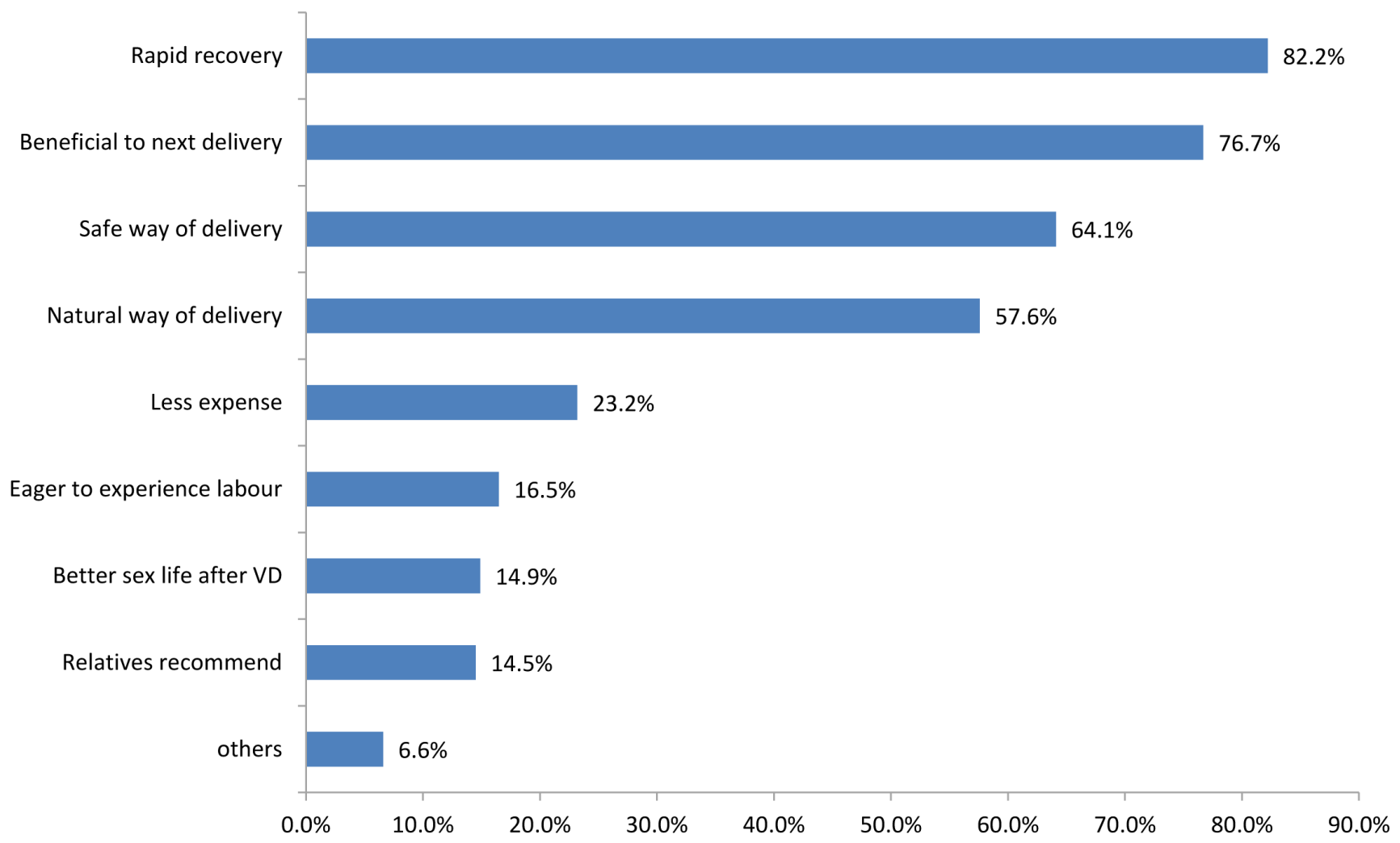

Figure 3 Frequency distribution of the reasons why women chose vaginal delivery (VD) in intent group at first interview. 
Table 2 Preferred mode and final mode of delivery of participating women $(n=814)$

\begin{tabular}{|c|c|c|c|c|c|}
\hline Outcome & $\begin{array}{l}\text { Intent to have } \\
\text { a second } \\
\text { child ( } n=417)\end{array}$ & $\begin{array}{l}\text { No Intent to } \\
\text { have a second } \\
\text { child ( } n=397)\end{array}$ & Crude RR (95\%Cl) & $\begin{array}{l}\text { Adjusted RR } \\
(95 \% \mathrm{Cl})\end{array}$ & $P$ value \\
\hline Caesarean delivery & $26(6.2 \%)$ & $71(17.9 \%)$ & $0.31(0.19$ to 0.49$) \ddagger$ & $0.35(0.20$ to 0.63$)$ & 0.001 \\
\hline Vaginal delivery or no preference (ref) ${ }^{*}$ & $391(93.8 \%)$ & $326(82.1 \%)$ & 1 & 1 & \\
\hline Vaginal delivery or no preference (ref)† & $316(75.7 \%)$ & $249(62.7 \%)$ & 1 & 1 & \\
\hline \multicolumn{6}{|l|}{ Final mode of delivery } \\
\hline overall cesarean delivery & $171(41.0 \%)$ & $200(50.4 \%)$ & $0.69(0.52$ to 0.90$) \ddagger$ & $0.84(0.60$ to 1.18$)$ & 0.31 \\
\hline Cesarean delivery on maternal request & $70(16.7 \%)$ & $115(29.0 \%)$ & $0.48(0.33$ to 0.71$) \ddagger$ & $0.56(0.37$ to 0.86$)$ & 0.008 \\
\hline Intrapartum cesarean delivery & $8(1.9 \%)$ & $12(3.0 \%)$ & $0.56(0.21$ to 1.51$)$ & 0.73 (0.26 to 2.09$)$ & 0.56 \\
\hline Vaginal delivery (ref) & $246(59 \%)$ & $197(49.6 \%)$ & 1 & 1 & \\
\hline
\end{tabular}

Data expressed as $\mathrm{n}(\%)$.

Adjusted for age, educational level, insurance, average income of the family, occupation, medical history, pregnancy complications, birth weight, maternal and neonatal morbidity.

*Seven women had no preference in the intent group and 13 women had no preference in no intent group. †No women chose no preference in both groups. $\ddagger \mathrm{P}<0.05$.

for the next delivery, which indicates a more cautious and rational view of $\mathrm{CD}$ in nulliparous women who want two children after implementation of China's two child policy.

It should be noted that there was a rapid increased preference for $\mathrm{CD}$ in both groups $(6.2 \%$ to $24.2 \%$ in the intent group and $17.9 \%$ to $37.3 \%$ in the no intent group), which was different from other studies. A survey conducted by Karlstrom et al found that preference for $\mathrm{CD}$ in Sweden was stated by $7.6 \%$ of women during mid pregnancy and by $7.0 \%$ in late pregnancy. ${ }^{31}$ Pang et al reported that $17.2 \%$ of women chose $\mathrm{CD}$ at 20 weeks' gestation which decreased to $12.7 \%$ at 37 weeks' gestation in nulliparous Hong Kong Chinese women. ${ }^{32}$ These two studies concluded that a decreasing proportion of women preferred $\mathrm{CD}$ with increasing gestational weeks. However, more recent studies have shown different conclusions, which are consistent with our results. Ji et al reported that the proportion of $\mathrm{CD}$ preference increased from $13.2 \%$ in the second trimester to $17.0 \%$ in the third trimester. ${ }^{18}$ Deng's survey also showed the same increase (25.1\% women preferred CD in in early pregnancy which increased to $28.4 \%$ in late pregnancy).$^{33}$ It is difficult to clarify the underlying reasons for such results, because whether a pregnant woman prefers a vaginal delivery or $\mathrm{CD}$ is ultimately determined by a variety of socioeconomic, medical, obstetric and neonatal factors. Nevertheless, there were some differences among these studies by comparing baseline and obstetric characteristics, which could partially explain the difference. First, the ratio of tertiary education was $51.5 \%$ and $39.3 \%$ in Karlstrom's and Pang's survey, and it was $71.9 \%$ and $68.2 \%$ in Ji's and Deng's study. However, the proportion in our study was $>80 \%$ ( $86.8 \%$ in the intent group and $83.9 \%$ in the no intent group), ranking the highest in these four studies. It seems that a higher education level was a strong exposure factor associated with increasing $\mathrm{CD}$ preference and final $\mathrm{CD}$, and has been proved in several studies. ${ }^{719}{ }^{34}$ Second, a relatively high proportion of women of advanced age $(1.4 \%$ of women in the intent group and $9.8 \%$ of women in the no intent group were $>35$ years of age) may also have resulted in the increase. ${ }^{19}$ Moreover, as the largest obstetric care and high risk pregnancy centre in Chongqing, many pregnant women with severe complications were transferred to our hospital; they may have had a negative influence when they chatted with other women. Also, nearly one-third of participating women were diagnosed with pregnancy complications (30.7\% in the intent group and $35.0 \%$ in the no intent group), leading to excessive worry about their delivery, even though most of these complications were not indications for CD.

In accordance with the decreased $\mathrm{CD}$ preference, the final CD rate decreased by nearly $10 \%$ and the CDMR rate decreased by more than $12 \%$ compared with the no intent group, and the decreases remained significant for CDMR after adjustment, even though the decrease in final CD was no longer significant. From this observational study, we concluded that the desire for a second 
child had a significant impact on nulliparous women choosing CD, particularly CDMR.

Notably, there remained a high CD rate $(45.6 \%)$ for nulliparous women, despite a large proportion of women who chose vaginal delivery $(85.6 \%)$ as their first choice at the first interview, or on admission (68.8\%). Several studies have shown similar findings. ${ }^{18} 35$ 36 $\mathrm{A}$ study conducted by Ji et al aiming at identifying factors contributing to the rapid rise in $\mathrm{CD}$ in Shanghai among nulliparous women reported that the CD preference was 13.2\% and $17 \%$ in the second and third trimesters, respectively, but $58.1 \%$ of women finally underwent $\mathrm{CD}$, including $34.9 \%$ of women who underwent surgery without any medical indications or based on maternal request. ${ }^{18}$ They concluded that doctor judgement plays an important role in the decision making. Similarly, our study showed the same result: $33.7 \%(125 / 371)$ of women who underwent $\mathrm{CD}$ had borderline indications, indicating that nearly one-third of women underwent $\mathrm{CD}$ without definite surgery criteria, and instead had only borderline indications based on the obstetrician's judgement. In addition to the tense doctor-patient relationship in China, a shortage of obstetricians and midwives to meet the demand for labour is also a key factor, and this shortage will become worse after implementation of the new policy. ${ }^{24}$ Therefore, any efforts to decrease this category of $\mathrm{CD}$ should focus on solving these issues in the next few years. On the one hand, enriched professional knowledge to appropriately use policies and guidelines should be developed. Also, strengthening communication skills with patients and their family members and paying more attention to labour are key to relieving the tensions in the doctor-patient relationship. ${ }^{37-39}$ On the other hand, reforming payments and the malpractice system, and increasing the number of nurses and midwives will be necessary to solve these shortages in the next few years. ${ }^{4}$

Interestingly, in our study, nearly half of participating women $(48.8 \%)$ did not intend to have a second child, which was contrary to the new population policy. This is common in China, particularly urban China, after over 30 years of the population control policy. Yi noted that only $13.2 \%$ of eligible couples and a lower ratio of urban residents applied for permission to have a second child. Economic pressures and time shortages were likely the main reasons for such low application rates. ${ }^{40}$ The results of a multiple choice question in our survey on reasons why women do not intend to have a second child also support Yi's conclusion. However, as the local government initiated the policy gradually, more women might change their mind, and a baby boom will likely occur.

Several limitations are worth mentioning. As a teaching hospital in the centre of Chongqing, $89.2 \%$ of women enrolled in our observation were from the urban population (data not shown). Also, in $85.4 \%$ of women, educational level was tertiary, which may have led to their lower intention of having a second child (only $51.2 \%$ of participating women intended to have a second child). It is widely known that women with higher levels of education have fewer children. ${ }^{41}$ Data from the Demographic and Health Surveys for 26 countries confirmed that higher education is consistently associated with lower fertility. ${ }^{42}$ Another study including 35212 Finnish women born in 1940-1950 found that women's education and socioeconomic position of the family were negatively associated with fertility. ${ }^{43}$ All of these studies indicated that women with a higher education level had a lower fertility intent. However, there were relatively small numbers of women with a primary or secondary educational level. Combined with this, fertility intent was ultimately determined by a variety of other factors, indicating that our data did not accord with this tendency (the rates of intent to have a second child were $61.9 \%, 42.9 \%$ and $52.1 \%$ in the primary or below, secondary and tertiary education groups).

As the largest obstetric care and high risk pregnancy centre in Chongqing, many pregnant women with severe complications are transferred to our hospital, resulting in a relatively high $\mathrm{CD}$ rate. Therefore, the results of our study may not reflect the preferences and conditions among Chinese nulliparous women living in other regions of China. Furthermore, given the relatively small sample size and the potential researchers' influences on the women's choices, there are limitations of generalisability when extrapolating the results of the present study to other regions. Although we performed a series of logistic regressions and calculated the adjusted RR to minimise this bias, the researchers' influence still existed because there was information bias. Also, the nature of the observational study, in particular that the no intent group had a much higher proportion of mothers at advanced age ( $\geq 35$ years) than the intent group $(9.8 \%$ vs $1.4 \%)$, residual confounding likely still existed that might have an effect on the association between exposure variables and outcomes.

\section{CONCLUSIONS}

In conclusion, this study confirms that women who intend to have a second child are less likely to demand $\mathrm{CD}$ at our institution after implementation of the new two child policy. The observed decrease was both statistically and clinically significant, and we believe that our findings will help policy makers promote better strategies to lower the high $\mathrm{CD}$ rate in mainland China.

Acknowledgements We are grateful to $Y X$ for her suggestions regarding the design of the study. We thank the nurse team for their help with participant recruitment and data collection.

Contributors JZ, YX and HQ designed the study. JZ, QL and XY performed the experiments. JZ and QL analysed and interpreted the data. JZ and XY drafted the article. $H Z$, NS and $H Q$ revised the article. $H Q$ designed the paper and approved the version to be published. All authors approved this version for publication.

Funding This work was financially supported by the National Natural Science Foundation of China (Nos 81520108013, 81471472 and 81601304), the National Key Research and Development Program "the research on birth defect prevention and control of reproductive health and" special emphasis (No 2016YFC1000407), the National Health and Family Planning Commission (No 201402006), the Ph.D. Programs Foundation of Ministry of Education of China (№ 2013550311003), the Innovation team Foundation of Chongqing Education Commission (No 
CXTDX201601014), the Establishment and Optimization of Common High-risk Fetal Diagnosis and Treatment Technology Standards and Specifications" from the National Health and Family Planning Commission, China (No 201402006) and the 111 Project (Nos Yuwaizhuan (2016)404 and Yuwaizhuan (2017)175).

Competing interests None declared.

Patient consent Obtained.

Ethics approval This project was approved by the institutional research ethics committee of Chongqing Medical University.

Provenance and peer review Not commissioned; externally peer reviewed.

Data sharing statement № additional data are available.

Open Access This is an Open Access article distributed in accordance with the Creative Commons Attribution Non Commercial (CC BY-NC 4.0) license, which permits others to distribute, remix, adapt, build upon this work non-commercially, and license their derivative works on different terms, provided the original work is properly cited and the use is non-commercial. See: http://creativecommons.org/ licenses/by-nc/4.0/

(C) Article author(s) (or their employer(s) unless otherwise stated in the text of the article) 2017. All rights reserved. No commercial use is permitted unless otherwise expressly granted.

\section{REFERENCES}

1. Betrán AP, Ye J, Moller AB, et al. The increasing trend in caesarean section rates: global, regional and national estimates: 1990-2014. PLoS One 2016;11:e0148343.

2. Villar J, Valladares E, Wojdyla D, et al. Caesarean delivery rates and pregnancy outcomes: the 2005 WHO global survey on maternal and perinatal health in Latin America. Lancet 2006;367:1819-29.

3. Lumbiganon P, Laopaiboon M, Gülmezoglu AM, et al. Method of delivery and pregnancy outcomes in Asia: the WHO global survey on maternal and perinatal health 2007-08. Lancet 2010;375:490-9.

4. Hellerstein S, Feldman S, Duan T.China's $50 \%$ caesarean delivery rate: is it too high? BJOG 2015;122(2):160

5. Liu Y, Li G, Chen Y, et al. A descriptive analysis of the indications for caesarean section in mainland China. BMC Pregnancy Childbirth 2014;14:410.

6. Hou L, Hellerstein S, Vitonis A, et al. Cross sectional study of mode of delivery and maternal and perinatal outcomes in mainland China. PLoS One 2017;12:e0171779.

7. Zhang J, Liu Y, Meikle S, et al. Cesarean delivery on maternal request in southeast China. Obstet Gynecol 2008;111:1077-82.

8. Li HT, Luo S, Trasande L, et al. Geographic variations and temporal trends in cesarean delivery rates in China, 2008-2014. JAMA 2017;317:69.

9. Clark SL, Belfort MA, Dildy GA, et al. Maternal death in the 21st century: causes, prevention, and relationship to cesarean delivery. Am J Obstet Gynecol 2008;199:36.e1-36.e5.

10. Liu S, Liston RM, Joseph KS, et al. Maternal mortality and severe morbidity associated with low-risk planned cesarean delivery versus planned vaginal delivery at term. CMAJ 2007;176:455-60.

11. Souza JP, Gülmezoglu A, Lumbiganon P, et al. Caesarean section without medical indications is associated with an increased risk of adverse short-term maternal outcomes: the 2004-2008 WHO Global Survey on Maternal and Perinatal Health. BMC Med 2010;8:71.

12. Karlström A, Lindgren $\mathrm{H}$, Hildingsson I. Maternal and infant outcome after caesarean section without recorded medical indication: findings from a Swedish case-control study. BJOG 2013;120:479-86.

13. Clark EA, Silver RM. Long-term maternal morbidity associated with repeat cesarean delivery. Am J Obstet Gynecol 2011;205:S2-S10.

14. Eshkoli T, Weintraub AY, Sergienko R, et al. Placenta accreta: risk factors, perinatal outcomes, and consequences for subsequent births. Am J Obstet Gynecol 2013;208:219.e1-219.e7.

15. Al-Zirqi I, Stray-Pedersen B, Forsén L, et al. Uterine rupture after previous caesarean section. BJOG 2010;117:809-20.

16. Landon MB, Hauth JC, Leveno KJ, et al. Maternal and perinatal outcomes associated with a trial of labor after prior cesarean delivery. N Engl J Med 2004;351:2581-9.
17. He Z, Cheng Z, Wu T, et al. The costs and their determinant of cesarean section and vaginal delivery: An exploratory study in Chongqing municipality, China. Biomed Res Int 2016;2016:1-9.

18. Ji $H$, Jiang $H$, Yang $L$, et al. Factors contributing to the rapid rise of caesarean section: a prospective study of primiparous Chinese women in Shanghai. BMJ Open 2015;5:e008994.

19. Tang S, Li X, Wu Z. Rising cesarean delivery rate in primiparous women in urban China: evidence from three nationwide household health surveys. Am J Obstet Gynecol 2006;195:1527-32.

20. Feng $X L, X u L$, Guo $Y$, et al. Factors influencing rising caesarean section rates in China between 1988 and 2008. Bull World Health Organ 2012;90:30-9.

21. Pan Y, Yang Xhong, He JP, et al. To be or not to be a doctor, that is the question: a review of serious incidents of violence against doctors in China from 2003-2013. J Public Health 2015;23:111-6.

22. The two-child policy in China: what to expect? Lancet 2013;382:1758.

23. Zeng Y, Hesketh T. The effects of China's universal two-child policy. Lancet 2016;388:1930-8.

24. Cheng PJ, Duan T. China's new two-child policy: maternity care in the new multiparous era. BJOG 2016;123:7-9.

25. Yaman Tunc S, Agacayak E, Sak S, et al. Multiple repeat caesarean deliveries: do they increase maternal and neonatal morbidity? J Matern Fetal Neonatal Med 2017;30:739-44.

26. Lee YM, D'Alton ME. Cesarean delivery on maternal request: maternal and neonatal complications. Curr Opin Obstet Gynecol 2008;20:1-601

27. Torloni MR, Betran AP, Souza JP, et al. Classifications for cesarean section: a systematic review. PLoS One 2011;6:e14566.

28. The expert consensus on cesarean delivery operation. Zhonghua Fu Chan Ke Za Zhi 2014;49:721-4.

29. Liu X, Landon MB, Cheng W, et al. Cesarean delivery on maternal request in China: what are the risks and benefits? Am J Obstet Gynecol 2015;212:817.e1-817.e9.

30. Liu X, Lynch CD, Cheng WW, et al. Lowering the high rate of caesarean delivery in China: an experience from Shanghai. BJOG 2016;123:1620-8.

31. Karlström A, Nystedt A, Johansson M, et al. Behind the myth-few women prefer caesarean section in the absence of medical or obstetrical factors. Midwifery 2011;27:620-7.

32. Pang MW, Lee TS, Leung AK, et al. A longitudinal observational study of preference for elective caesarean section among nulliparous Hong Kong Chinese women. BJOG 2007;114:623-9.

33. Deng W, Klemetti R, Long Q, et al. Cesarean section in Shanghai: women's or healthcare provider's preferences? BMC Pregnancy Childbirth 2014;14:285.

34. Moosavi A, Sheikhlou SG, Sheikhlou SG, et al. Influencing factors in choosing delivery method: Iranian primiparous women's perspective. Electron Physician 2017;9:4150-4.

35. Mazzoni A, Althabe F, Gutierrez L, et al. Women's preferences and mode of delivery in public and private hospitals: a prospective cohort study. BMC Pregnancy Childbirth 2016;16:34.

36. Wang L, Xu X, Baker P, et al. Patterns and associated factors of caesarean delivery intention among expectant mothers in china: Implications from the implementation of China's new national twochild policy. Int J Environ Res Public Health 2016;13:686.

37. Li Z, Yan CM, Shi L, et al. Workplace violence against medical staff of Chinese children's hospitals: a cross-sectional study. PLoS One 2017;12:e0179373.

38. Zhou C, Mou H, Xu W, et al. Study on factors inducing workplace violence in Chinese hospitals based on the broken window theory: a cross-sectional study. BMJ Open 2017;7:e016290.

39. Shi L, Zhang D, Zhou C, et al. A cross-sectional study on the prevalence and associated risk factors for workplace violence against Chinese nurses. BMJ Open 2017;7:e013105.

40. Zeng Y, Hesketh T. The effects of China's universal two-child policy. Lancet 2016;388:1930-8.

41. Lutz W, Kc S. Global human capital: integrating education and population. Science 2011;333:587-92.

42. Castro Martin T. Women's education and fertility: results from 26 Demographic and Health surveys. Stud Fam Plann 1995;26:187-202.

43. Nisén J, Myrskylä M, Silventoinen K, et al. Effect of family background on the educational gradient in lifetime fertility of Finnish women born 1940-50. Popul Stud 2014;68:321-37. 